\title{
LA FIGURA DEL TRADUCTOR EN LAS NORMAS PROCESALES ESPAÑOLAS. ANÁLISIS DE LOS ÓRDENES JURISDICCIONALES CIVIL, PENAL, CONTENCIOSO-ADMINISTRATIVO Y SOCIAL
}

\author{
María de las Heras Caba \\ Traductora-Intérprete Jurada de inglés \\ Doctora en Traducción e Interpretación por la Universidad de Granada \\ Correo electrónico: delasherascaba@gmail.com
}

Resumen: En este artículo pretendemos llevar a cabo un repaso por todas aquellas normas procesales, con respecto a los órdenes jurisdiccionales civil, penal, contenciosoadministrativo y social, que hagan referencia a la traducción, con el objeto de identificar la configuración legal de la figura del traductor en las normas procesales españolas.

Palabras clave: traducción jurídica, traducción judicial, traducción jurada, práctica profesional de la traducción judicial, órdenes jurisdiccionales.

\begin{abstract}
In this article we want to review those Spanish procedural rules with regard to the civil, criminal, administrative and labour jurisdictional orders, which refer to translation issues, in order to identify how the figure of the translator is regulated in the Spanish procedural law.
\end{abstract}

Keywords: legal translation, judicial translation, sworn translation, judicial translation practice, Spanish jurisdictional orders. 


\section{Introducción}

El papel del traductor en las normas procesales españolas ha ido evolucionando a lo largo de los años. La situación actual de dicha figura en los distintos órdenes jurisdiccionales es compleja, pues no solo es evidente la falta de profesionalización de la figura del traductor en este ámbito, sino que además la normativa ha ido sufriendo constantes modificaciones con el paso de los años.

En este artículo queremos hacer una reflexión en torno a la traducción en las normas procesales, centrándonos exclusivamente en la figura del traductor, que no intérprete, dentro de los cuatro órdenes jurisdiccionales: civil, penal, contencioso-administrativo y social.

Asimismo, hemos de subrayar que no es nuestra intención llevar a cabo una mera compilación normativa, al contrario, en el presente artículo pretendemos realizar un análisis de la configuración legal que se ha dado a dicha figura en las normas procesales españolas. Para ello, y siguiendo a Gimeno Sendra ${ }^{1}$ en cuanto a la clasificación que hace cuando se refiere a las principales leyes procesales, examinaremos, por una parte, las normas procesales especializadas, propias y de aplicación directa en cada uno de los órdenes jurisdiccionales, y, por otra parte, las normas procesales comunes a todos ellos. No obstante, solo consideraremos aquellas normas que, bien de manera somera o bien en profundidad, aludan o regulen la traducción y el papel del traductor.

Ahora bien, a efectos de contextualizar previamente nuestro artículo, dado que nos movemos en un campo híbrido, de posible interés tanto para juristas como para traductores, llevaremos a cabo primero un repaso por aquellos conceptos que consideramos básicos para el desarrollo y buen entendimiento del presente estudio. Así pues, a continuación, haremos referencia, por un lado, al concepto de jurisdicción, proceso y de derecho procesal y, por otro lado, continuaremos haciendo mención a las implicaciones de la traducción y al significado y alcance del concepto de traducción jurídica, traducción judicial y traducción jurada.

\footnotetext{
${ }^{1}$ Gimeno Sendra, V., Introducción al Derecho Procesal, Madrid, Castillo de Luna, 2015, págs. 411 y 412.
} 


\section{Jurisdicción, proceso y derecho procesal}

A la hora de determinar el concepto de jurisdicción, proceso y derecho procesal, son múltiples los autores que arrojan luz sobre la materia y diversas las definiciones dadas. Por nuestra parte, sin intención de hacer una enumeración de las mismas y con el mero propósito de precisar el campo jurídico en el que se desarrolla nuestro análisis, únicamente aludiremos en este apartado a aquellas reflexiones y definiciones que consideremos más esclarecedoras.

\section{Jurisdicción}

En cuanto al concepto de jurisdicción, Gimeno Sendra entiende que esta puede ser definida como:

el Poder Judicial, integrado por jueces y magistrados, quienes, por su independencia y sumisión a la Ley y al Derecho, ejercen en exclusiva la potestad jurisdiccional y, en consecuencia, expresamente están legitimados para la resolución jurídica, motivada, definitiva e irrevocable de los conflictos intersubjetivos y sociales, para la protección de los derechos subjetivos, el control de la legalidad y la complementación del ordenamiento jurídico ${ }^{2}$.

Montero Aroca $^{3}$, en cambio, señala que «la jurisdicción es la potestad dimanante de la soberanía del Estado, ejercida exclusivamente por los juzgados y tribunales, integrados por jueces y magistrados independientes, de garantía y tutela de los derechos de las personas en el caso concreto, juzgando de modo irrevocable y ejecutando lo juzgado».

De estas definiciones se deduce que Gimeno Sendra destaca como nota esencial de la jurisdicción su condición de poder, pues considera esta como un poder independiente de los demás poderes del Estado, mientras que para Montero Aroca lo relevante es la potestad ejercida exclusivamente por los juzgados y tribunales.

\footnotetext{
2 Ibíd., pág. 40.

${ }^{3}$ Montero Aroca, J., G, Gómez Colomer, J. L. y Barona Vilar, S., Derecho Jurisdiccional I. Parte General, Valencia, Tirant Lo Blanch, 2015, pág. 65.
} 
En nuestro ordenamiento jurídico, la Constitución Española de 1978, en adelante CE, se refiere y regula la jurisdicción en el Título VI, Del Poder Judicial. En concreto, el artículo 117, en los apartados 1, 3 y 5, dispone lo siguiente:

1. La justicia emana del pueblo y se administra en nombre del Rey por Jueces y Magistrados integrantes del poder judicial, independientes, inamovibles, responsables y sometidos únicamente al imperio de la ley.

3. El ejercicio de la potestad jurisdiccional en todo tipo de procesos, juzgando y haciendo ejecutar lo juzgado, corresponde exclusivamente a los Juzgados y Tribunales determinados por las leyes, según las normas de competencia y procedimiento que las mismas establezcan.

5. El principio de unidad jurisdiccional es la base de la organización y funcionamiento de los Tribunales. La ley regulará el ejercicio de la jurisdicción militar en el ámbito estrictamente castrense y en los supuestos de estado de sitio, de acuerdo con los principios de la Constitución.

En igual sentido se pronuncia la Ley Orgánica 6/1985, de 1 de julio, del Poder Judicial, en lo sucesivo LOPJ, que dedica su Título Preliminar al Poder Judicial y al ejercicio de la potestad jurisdiccional.

De la lectura de estos preceptos se infiere que la jurisdicción se configura en nuestro ordenamiento jurídico de la siguiente manera:

Es un poder independiente de los demás poderes del Estado, sometido a la ley y al Derecho.

$>$ El ejercicio de la potestad jurisdiccional en todo tipo de procesos, juzgando y haciendo ejecutar lo juzgado, se otorga con exclusividad a los Juzgados y Tribunales.

Está informada por el principio de unidad jurisdiccional. 
Ahora bien, a la jurisdicción se le asigna una función. A este respecto, señala Gimeno Sendra ${ }^{4}$ que la Jurisdicción tiene una función genérica que es la resolución de los conflictos, intersubjetivos y sociales, mediante la aplicación del derecho objetivo, pero dicha función se realiza y concreta en la protección de los derechos subjetivos, en el control de la legalidad y en la complementación del ordenamiento.

En análogo sentido, Moreno Catena ${ }^{5}$ afirma que «la jurisdicción representa un medio jurídico civilizado para la pacificación de conflictos sociales» y que «para lograr la pacificación de los conflictos jurídicos la jurisdicción integra básicamente dos funciones: la tutela de los derechos subjetivos y el control de las normas jurídicas». Además, manifiesta que:

Cuando se trata de resolver un conflicto jurídico y se solicita la intervención de la jurisdicción, ésta debe actuar en todo caso dando la oportuna respuesta, de modo que en la actualidad los tribunales no pueden negarse a resolver, ni siquiera cuando no encuentran la norma a aplicar o cuando ésta no existe; por lo tanto, en esa función de la defensa de la ley los tribunales habrán de realizar no sólo una labor de interpretación y aplicación de las normas jurídicas, sino también una actividad de creación del Derecho, cuando no haya norma y exista un conflicto jurídico que componer6.

Asimismo, como hemos reseñado anteriormente, en el ordenamiento jurídico español se parte del principio de unidad jurisdiccional. El principio de unidad jurisdiccional, dice el artículo 117.5 de la CE transcrito, es la base de la organización y funcionamiento de los Tribunales. Dicho principio se recoge también en el artículo 3.1 de la LOPJ cuando dice que «la jurisdicción es única y se ejerce por los Juzgados y Tribunales previstos en esta Ley, sin perjuicio de las potestades jurisdiccionales reconocidas por la Constitución a otros órganos».

\footnotetext{
${ }^{4}$ Gimeno Sendra, V., ob. cit., págs. 47 y 48.

${ }^{5}$ Moreno Catena, V. y Cortés Domínguez, V., Introducción al Derecho Procesal, Tirant Lo Blanch, Valencia, 2015, pág. 45.

${ }^{6}$ Ibíd. pág. 46.
} 
No obstante, como reconoce Asencio Mellado7, esta unidad jurisdiccional debe ser matizada en el sentido de que los Jueces y Tribunales integrantes del Poder Judicial pueden coexistir con otros órganos jurisdiccionales que se encuentren constitucionalmente reconocidos, tal y como establece el artículo 3.1 de la LOPJ cuando dice expresamente: «sin perjuicio de las potestades jurisdiccionales reconocidas por la Constitución a otros órganos». Para Gimeno Sendra 8 «es claro que no se ha querido efectuar en nuestro ordenamiento una consagración rotunda y radical del referido principio de unidad, toda vez que la propia Constitución anunció la instauración de nuevos órganos jurisdiccionales, no encuadrables formalmente en el Poder Judicial».

Sin embargo, Moreno Catena 9 sostiene que «el principio de unidad jurisdiccional no se ve afectado por el establecimiento de diferentes tribunales, que en España conforman cuatro órdenes jurisdiccionales: el orden civil, el penal, el contencioso-administrativo y el social», al igual que entiende que «Tampoco desobedece el principio de unidad jurisdiccional la creación de tribunales especializados, que ejercen la potestad jurisdiccional sobre una materia o sobre un conjunto de materias». En el mismo sentido se pronuncia Asencio Mellado 10 cuando declara que «que el Poder Judicial sea único no impide su división en razón de criterios preestablecidos legalmente en función de la materia, sujetos, tiempo, lugar etc...», a lo que añade: «Lo incorrecto es hablar de diversidad de Jurisdicciones en el seno del Poder Judicial. No es técnicamente correcto, aunque lo sea coloquialmente, referirse a la Jurisdicción civil, penal social o administrativa».

Así pues, en esta jurisdicción única, los órganos que ejercen la función están, como hemos apuntado, integrados en distintos órdenes jurisdiccionales. Estos órdenes jurisdiccionales vienen especificados en el artículo 9 de la LOPJ y tienen determinada la competencia en los artículos 22 a 25, ambos inclusive, de dicho texto legal. Luego, a tenor del artículo 9.2, 3, 4 y 5 de la LOPJ, podemos afirmar que los Tribunales y Juzgados de los distintos órdenes conocerán de las siguientes materias:

\footnotetext{
${ }^{7}$ Asencio Mellado, J. M., Introducción al Derecho Procesal, Tirant Lo Blanch, Valencia, 2015, pág. 61.

8 Gimeno Sendra, V., ob. cit., pág. 82.

${ }^{9}$ Moreno Catena, V. y Cortés Domínguez, V., ob. cit., pág. 61.

10 Asensio Mellado, J. M., ob. cit., pág. 62.
} 
2. Los $[\ldots]$ del orden civil conocerán, además de las materias que les son propias, de todas aquellas que no estén atribuidas a otro orden jurisdiccional $[\ldots]$

3. Los del orden jurisdiccional penal tendrán atribuido el conocimiento de las causas y juicios criminales, con excepción de los que correspondan a la jurisdicción militar.

4. Los del orden contencioso-administrativo conocerán de las pretensiones que se deduzcan en relación con la actuación de las Administraciones públicas sujeta al derecho administrativo, con las disposiciones generales de rango inferior a la ley y con los reales decretos legislativos en los términos previstos en el artículo 82.6 de la Constitución, de conformidad con lo que establezca la Ley de esa jurisdicción. También conocerán de los recursos contra la inactividad de la Administración y contra sus actuaciones materiales que constituyan vía de hecho $[\ldots]$

Conocerán, asimismo, de las pretensiones que se deduzcan en relación con la responsabilidad patrimonial de las Administraciones públicas y del personal a su servicio, cualquiera que sea la naturaleza de la actividad o el tipo de relación de que se derive. Si a la producción del daño hubieran concurrido sujetos privados, el demandante deducirá también frente a ellos su pretensión ante este orden jurisdiccional. Igualmente conocerán de las reclamaciones de responsabilidad cuando el interesado accione directamente contra la aseguradora de la Administración, junto a la Administración respectiva.

También será competente este orden jurisdiccional si las demandas de responsabilidad patrimonial se dirigen, además, contra las personas o entidades públicas o privadas indirectamente responsables de aquéllas.

5. Los del orden jurisdiccional social conocerán de las pretensiones que se promuevan dentro de la rama social del derecho, tanto en conflictos individuales como colectivos, así como las reclamaciones 
en materia de Seguridad Social o contra el Estado cuando le atribuya responsabilidad la legislación laboral.

\section{Proceso}

Sentado lo anterior en cuanto a la jurisdicción, es preciso reseñar que el instrumento que tiene la jurisdicción para cumplir la función que se le asigna es el proceso; sin proceso, tal como apunta Montero Aroca 11 , no hay ejercicio de la función jurisdiccional. De hecho, proclama el autor, «éste no es sino el instrumento por medio del que actúa el órgano dotado de potestad jurisdiccional»; es simplemente, afirma, «el medio a través del que los órganos del Estado con potestad jurisdiccional han de cumplir la función que se les asigna constitucionalmente», al igual que «el medio por el que los particulares pueden ver satisfecho el derecho a la tutela judicial que se les reconoce constitucionalmente».

Si bien la doctrina coincide en la consideración del proceso como instrumento de la función jurisdiccional, son diversas las definiciones que se han dado del mismo al determinar su concepto. Así, para Gimeno Sendra, el proceso es

el conjunto de derechos constitucionales de incidencia procesal, posibilidades, obligaciones y cargas, que asisten a los sujetos procesales como consecuencia del ejercicio del derecho de acción y de la interposición de la pretensión, cuya realización, a través de los oportunos actos procesales, origina la aparición de sucesivas situaciones procesales, informadas por los principios de contradicción e igualdad, desde las que las partes examinan sus expectativas de una Sentencia favorable que ponga fin al conflicto mediante la satisfacción definitiva de sus respectivas pretensiones y resistencias 12 .

Por su parte, Asencio Mellado13 afirma que el proceso, entendido en sentido amplio, es un «mecanismo constituido por una sucesión de actos perfectamente regulados a los que las partes y el órgano jurisdiccional deben sujetarse en tanto que en sí mismo se erige en

\footnotetext{
${ }^{11}$ Montero Aroca, J., G, Gómez Colomer, J. L. y Barona Vilar, S., ob. cit., págs. 231 y 227.

12 Gimeno Sendra, V., ob. cit., pág. 304.

13 Asensio Mellado, J. M., ob. cit., pág. 26.
} 
una garantía de justicia y de evitación de posibles arbitrariedades cometidas por el propio Estado».

Además, sirve el proceso, como apuntan Fernández, Rifa y Valls ${ }^{14}$, a una doble finalidad, esto es, por un lado «pone en condiciones al órgano jurisdiccional de decidir si procede otorgar o denegar la tutela jurídica pedida», mientras que, por otro lado, si resulta que la tutela debe concederse, «sirve el proceso para precisar el modo y la forma en que la tutela cuya existencia se reconoció debe ser efectivamente concedida».

En palabras de Gimeno Sendra 15 , el proceso está arbitrado para «la solución definitiva e irrevocable, a través de la aplicación del Derecho objetivo, de los conflictos intersubjetivos y sociales que en él se planteen» al igual que para «la satisfacción de las pretensiones y resistencias».

Ahora bien, hemos de tener en cuenta que al determinar la naturaleza jurídica del proceso son diversas las teorías que se formulan, entendiendo el proceso como contrato, cuasi contrato, relación jurídica y situación jurídica. Sin ánimo de entrar en una exposición detallada de cada una de ellas, nos vamos a centrar solo en algunas.

Así, Fernández, Rifa y Valls 16 afirman que «el del "proceso" es un concepto jurídico primario, autónomo, yuxtaponible -que no subsumible- a otros conceptos jurídicos, como el de relación jurídica, situación jurídica, etc»; Montero Aroca17, en cambio, señala que «el proceso no tiene naturaleza jurídica porque no es una especie que se pueda encuadrar en un género; el proceso es por sí mismo un género, no encuadrable en otro superior»; sin embargo, Cortés Domínguez ${ }^{18}$ manifiesta que «desde el punto de vista jurídico, la relación existente entre Juez y partes y éstas entre sí, debe explicarse dentro del ámbito de la relación jurídica, en la que fundamentalmente no existen derechos y obligaciones, sino derechos, poderes, facultades y cargas y, muy excepcionalmente, obligaciones».

\footnotetext{
14 Fernández, M. A., Rifa, J. M. y Valls, J. F., Derecho Procesal Práctico, Tomo I, Editorial Centro de Estudios Ramón Areces, S. A., Madrid, 1995, pág. 390.

15 Gimeno Sendra, V., ob. cit., pág. 313.

16 Fernández, M. A., Rifa, J. M. y Valls, J. F., ob. cit., pág. 390.

17 Montero Aroca, J., G, Gómez Colomer, J. L. y Barona Vilar, S., ob. cit., pág. 229.

18 Moreno Catena, V. y Cortés Domínguez, V., ob. cit., pág. 242.
} 
Por último, y con ello concluimos esta conceptualización del proceso, cabe apuntar que no hay un único tipo de proceso, sino que existe una variedad de tipos de procesos. En la doctrina el conjunto de procesos que contempla nuestro ordenamiento, en cuya consideración individualizada no vamos a entrar, han sido clasificados con arreglo a distintos criterios según cada autor.

Para Cortés Domínguez ${ }^{19}$ «existen tantas clases de procesos cuantos órdenes jurisdiccionales», por consiguiente, existen procesos civiles, procesos penales, procesos contenciosos-administrativos y procesos laborales o sociales. Es más, dentro de cada una de esas clases de procesos, existen, prosigue el autor:

procesos declarativos, de ejecución o cautelares que cubren [...] los distintos fines que se alcanzan con el proceso. Y dentro de cada uno de estos procesos, podemos distinguir los procesos ordinarios, que están pensados para la tutela de la generalidad de los derechos, y de los especiales, que son creados para la de ciertos derechos, o para la tutela especial de derechos que normalmente son tutelados a través del proceso ordinario.

Gimeno Sendra 20 , por el contrario, declara que los procesos pueden ser clasificados en declarativos, cuyo objeto es «declarar la existencia de un derecho subjetivo o relación jurídica, modificarla, constituirla o anularla, o condenar al deudor al cumplimiento de una determinada prestación», y de ejecución, destinados a la «realización judicial del derecho del acreedor reconocido en dicho título o sentencia firme». Los procesos declarativos los clasifica, a su vez, con arreglo a distintos criterios:

$>$ Atendiendo a la amplitud o limitación de su objeto y a la extensión de los efectos de la sentencia, pueden ser ordinarios, sumarios y especiales.

D De conformidad con la naturaleza de la relación jurídico material debatida se distinguen procesos para la aplicación del derecho público y del derecho privado, perteneciendo al primer grupo el proceso penal, el constitucional y el contencioso-administrativo y al segundo el proceso civil y el de trabajo.

\footnotetext{
19 Ibíd. pág. 249.

20 Gimeno Sendra, V., ob. cit., pág. 338.
} 


\section{Derecho procesal}

En cuanto al derecho procesal, este, en una primera aproximación, puede ser definido como el conjunto de normas que regulan el proceso. Según Cortés Domínguez, el derecho procesal es el conjunto de normas que regulan los requisitos y los efectos del proceso, es más, afirma que:

Al ser el Derecho procesal el conjunto de normas que regulan los requisitos y efectos del proceso, en él no solo hay que incluir las que podemos denominar normas procedimentales (normas estrictamente reguladoras del proceso), sino también aquellas otras que denominamos orgánicas, en razón a que regulan la creación de los órganos judiciales, así como la actividad y coordenadas dentro de las cuales actuarán los mismos 21 .

Montero Aroca 22 , en cambio, señala que el derecho procesal, que según él debería ser llamado derecho jurisdiccional, «en la actualidad no es sólo el derecho del proceso, pues este no es ni el único ni el más importante concepto de aquél». Apunta que «la doctrina ha sido consciente de que otras realidades, aparte de la del proceso, son reguladas por normas que ella misma califica de procesales y [...] incluye dentro del Derecho procesal algo más que el proceso». Según este autor, el derecho jurisdiccional, que tiene la naturaleza de derecho público, ha de tener el siguiente contenido:

1. ${ }^{\circ}$ Las normas que se refieren a la jurisdicción misma, incluyendo las de la organización judicial y las configuradoras del estatuto jurídico de aquéllos a los que se confiere la potestad jurisdiccional (jueces y magistrados) y de aquéllos que colaboran (Ministerio fiscal, abogados y procuradores) o auxilian (personal al servicio de la Administración de Justicia) en el ejercicio de esa potestad.

2. Las normas que regulan el derecho de acción o derecho a la jurisdicción, incluidas las que facilitan su ejercicio, como la asistencia jurídica gratuita, y

\footnotetext{
${ }^{21}$ Moreno Catena, V. y Cortés Domínguez, V., ob. cit., pág. 23.

22 Montero Aroca, J., G, Gómez Colomer, J. L. y Barona Vilar, S., ob. cit., págs. 33 y 355.
} 
$3 .^{\circ}$ Las normas que conforman el proceso, comprendiendo tanto las que regulan los actos, como sus sujetos, presupuestos, contenidos y efectos.

Siguiendo esta misma línea argumental de que el derecho procesal es algo más que el conjunto de normas que regulan el proceso, Gimeno Sendra propone una definición en la que entiende el derecho procesal como

el conjunto de normas del Derecho público que regula la Jurisdicción, los presupuestos procesales, los derechos, posibilidades, cargas $\mathrm{y}$ obligaciones procesales, los actos procesales, las resoluciones del órgano jurisdiccional, la sentencia y sus efectos, así como los medios de impugnación, las medidas cautelares y resoluciones provisionales y el proceso de ejecución 23 .

En último lugar, recogemos también la definición de Asencio Mellado ${ }^{24}$, que considera que «el Derecho procesal, en un sentido muy general [...] puede ser definido como el conjunto de normas jurídicas, parte integrante del ordenamiento estatal, que se caracteriza por servir para la aplicación del derecho objetivo por los órganos jurisdiccionales al caso concreto». Puede afirmarse, añade, «que el derecho procesal es aquella parte del ordenamiento jurídico que regula la actuación de los órganos jurisdiccionales y de las partes en el seno del proceso con el fin de la aplicación del derecho al caso concreto cuya resolución se solicita».

Así pues, a tenor de las definiciones doctrinales expuestas, podemos concluir, entonces, que el derecho procesal se caracteriza por lo siguiente:

El derecho procesal pertenece a la categoría del derecho público.

$>$ Sus normas son imperativas, no cabe derogarlas por voluntad de las partes y al ser imperativas, deben aplicarse en todo caso.

$>$ Pertenece al estudio del derecho procesal todo lo relativo a la jurisdicción.

Asimismo, corresponde al derecho procesal el estudio del proceso.

$>$ Y posee un carácter instrumental, en cuanto que tiene por finalidad la de servir a la aplicación jurisdiccional del derecho material al caso concreto.

23 Gimeno Sendra, V., ob. cit., pág. 402.

24 Asensio Mellado, J. M., ob. cit., pág. 23. 


\section{La traducción: la traducción jurídica, judicial y jurada}

Una vez examinado todo lo relacionado con la jurisdicción, el proceso y el derecho procesal, resulta necesario distinguir, a continuación, entre los distintos tipos de traducción relacionados con este artículo y concretar, además, el alcance de la traducción y su diferenciación de la interpretación.

La traducción es definida en el diccionario de la Real Academia Española como «la acción y efecto de traducir», esto es, «expresar en una lengua lo que está escrito o se ha expresado antes en otra». Lo cual es correcto hasta cierto punto, pues, a pesar de que la anterior definición determina adecuadamente el concepto de traducción, no hace, sin embargo, diferenciación alguna entre lo que supone traducir e interpretar; al contrario, a nuestro modo de ver genera unas expectativas ambiguas respecto a la función del traductor.

La traducción y la interpretación son dos actividades inevitablemente interrelacionadas entre sí, pues ambas conllevan trabajar con diferentes lenguas, trasladando un mensaje desde una lengua A hacia una lengua $\mathrm{B}$, haciendo posible, con ello, la comunicación entre distintos idiomas. No obstante, muchas personas no son conscientes de la verdadera diferencia entre la traducción y la interpretación, profesiones muy distintas que precisan de habilidades diferentes: cuando hablamos de traducción, hacemos referencia únicamente a la comunicación escrita, mientras que cuando nos referimos a la interpretación hacemos alusión a la comunicación oral.

Sin ánimo de profundizar de manera individualizada en las implicaciones de cada una de estas profesiones, centraremos este apartado y el presente artículo, tal y como ya habíamos dispuesto, en el papel del traductor en las normas procesales españolas, dejando a un lado la figura y cometido del intérprete en los órdenes jurisdiccionales.

Si preguntásemos a cualquier persona no experto en el campo de la traducción las implicaciones que conlleva la práctica de la traducción, dudo mucho que alguien fuera consciente de la complejidad intrínseca en la práctica de la misma. Pocos saben que para traducir no basta con conocer con rigor la lengua en cuestión, pues como bien 
reconoce Brumme 25 , «no se entiende al traductor como un mero transmisor entre dos lenguas, sino como un especialista bi o multicultural que tiene que recrear, en una situación determinada, para una cultura meta, un texto impregnado de una cultura origen».

Una vez asimilado esto, que la traducción es un proceso comunicativo, de carácter textual, que tiene lugar en una situación comunicativa determinada y que supone una mediación entre culturas, podemos comprender, entonces, que esta se puede describir, además, tal y como apunta Mayoral Asensio 26 , desde dos puntos de vista distintos: según el grado de especialización del texto traducido, hablando en este caso de traducción general o traducción especializada; o según la materia sobre la que versa el propio documento, distinguiéndose, por ejemplo, la traducción jurídica de la traducción científica o de la traducción técnica, entre muchas otras.

Sin embargo, como bien afirma Gallardo San Salvador 27 , «la cuestión se complica cuando se trata de transmitir un acto de comunicación especializado», pues, como infiere la autora, «el traductor no tiene un conocimiento del campo temático con el que cuenta el especialista y tendrá que llegar a adquirirlo para, primero, comprender el texto, y después proceder a transferir ese conocimiento especializado y transmitirlo a su receptor». Luego, si además, como hemos visto, todo texto, con independencia de la especialidad que lo caracteriza, está marcado por aspectos culturales propios de la sociedad donde se produce, deducimos entonces que cualquier persona simplemente conocedora de un idioma no posee la habilidad precisa para traducir adecuadamente un documento y mucho menos si estamos ante un documento especializado.

Ahora bien, la definición y el alcance de cada uno de los tipos de traducción existentes es un tema en constante controversia debido a la falta de consenso entre los diferentes autores, pues no siempre resulta fácil establecer de manera categórica los límites de los

\footnotetext{
25 Brumme, J., «La traducción de la cultura». Espéculo, Universidad Complutense de Madrid. [En línea] Disponible en: https://pendientedemigracion.ucm.es/info/especulo/ele/trad_cul.html [Fecha de consulta: 25/07/2016].

${ }^{26}$ Mayoral Asensio, R., «Specialised Translation: a Concept in Need of Revision». Babel, 53(1), 2007, pág. 48.

${ }^{27}$ Gallardo San Salvador, N., «El lenguaje jurídico ante un proceso de renovación y modernización», en C. Navarro, Terminología, traducción y comunicación especializada. Homenaje a Amelia de Irazazábal. Actas del Congreso Internacional 11-12 de octubre de 2007, Edizioni Fiorini, Verona, 2008, pág. 158.
} 
distintos tipos de traducción especializada. En el caso que nos ocupa, para hacer referencia a la traducción en las normas procesales españolas se habla tanto de traducción jurídica como de traducción judicial y, en algunas ocasiones, como comprobaremos más adelante cuando citemos la normativa, de traducción jurada $\mathrm{u}$ oficial.

A grandes rasgos, entendemos por traducción jurídica toda actividad traslaticia caracterizada por la traducción de textos de naturaleza jurídica o, en su defecto, de textos inmersos en una situación jurídica determinada. Sin embargo, también es cierto que hay autores, como Ortega Arjonilla 28 , que defienden una evidente separación entre la traducción jurídica y la traducción judicial, pues, a pesar de que la traducción judicial conlleva en muchos casos la traducción de textos de naturaleza jurídica, igualmente es cierto que en el ámbito judicial no todos los documentos objeto de traducción son siempre de esta naturaleza, pues asimismo se pueden requerir traducciones de documentos de muy variada índole, ya sean documentos personales, jurídicos, informes técnicos, etc, es decir, cualquier documento que sea admitido por un juez en un sumario.

Así pues, y citando a este autor ${ }^{29}$, cuando hablamos de traducción judicial estamos haciendo referencia a «un tipo de traducción especializada, cercana, por la naturaleza de algunos de los documentos de su competencia, a la traducción jurídica», aunque también, prosigue el autor, hablamos de un tipo de traducción que, además, «se encuentra [igualmente] cerca de la traducción jurada porque obliga al traductor a responsabilizarse ante la Administración de las decisiones adoptadas en el proceso de traducción y del resultado final de éste».

En último lugar, en cuanto a la traducción jurada, este es el apelativo que recibe en España la traducción oficial llevada a cabo por un Traductor-Intérprete Jurado debidamente acreditado a tal efecto por el Ministerio de Asuntos Exteriores y de Cooperación (MAEC) para traducir, de manera íntegra y fidedigna, cualquier texto desde y hacia el idioma para el que ha sido autorizado. Para dicha acreditación es

\footnotetext{
28 Ortega Arjonilla, E. «La traducción jurídica, jurada y judicial: aspectos teóricos, metodológicos y profesionales», en E. Monzó y A. Borja, La traducción y la interpretación en las relaciones jurídicas internacionales, Castellón de la Plana, Universitat Jaume I, 2005, págs. 113-131.

${ }^{29}$ Ibíd., pág. 119.
} 
necesario superar un examen, convocado por la Subsecretaría del Ministerio de Asuntos Exteriores y de Cooperación de conformidad con lo dispuesto en la Orden AEC/2125/2014, de 6 de noviembre, por la que se dictan normas sobre los exámenes para la obtención del título de Traductor-Intérprete Jurado, cuyos requisitos de participación, según el artículo 8.1 de dicha Orden, son los siguientes:

Ser mayor de edad

Tener la nacionalidad española o de cualquier otro Estado miembro de la Unión Europea o del Espacio Económico Europeo.

$>$ Poseer un título español de Graduado o Licenciado, o un título extranjero que haya sido homologado a alguno de aquéllos por el Ministerio de Educación, Cultura y Deporte.

En este caso, a diferencia de la traducción jurídica, la traducción jurada no se circunscribe a ningún campo de especialidad concreto, en consecuencia, al igual que ocurre en el caso de la traducción judicial, cualquier documento puede ser objeto de traducción jurada, desde una carta personal hasta un poder notarial. No obstante, esta no es la única diferencia que la caracteriza, pues, como ya hemos referido, aparte de que este tipo de traducción solo se puede llevar a cabo por un Traductor-Intérprete Jurado habilitado por el MAEC, asimismo se distingue de la traducción jurídica y, también, de la traducción judicial, en que esta ha de incluir una certificación que acredite, junto con la firma y sello del Traductor-Interprete Jurado, la veracidad y exactitud de la traducción, adquiriendo con ello un carácter oficial que otras traducciones no poseen.

\section{Análisis normativo}

Comenzamos ahora nuestro análisis normativo adentrándonos en los distintos órdenes jurisdiccionales. Para ello, haremos un recorrido por las diversas normas procesales en las que, de forma explícita, se regule la traducción en el orden jurisdiccional civil, penal, contencioso-administrativo y social.

\subsection{Orden jurisdiccional civil}

En este apartado vamos a analizar las normas procesales especializadas, propias y de aplicación directa en el orden civil con la finalidad de determinar la regulación que las 
mismas realizan de la figura del traductor. En primer lugar, examinaremos la ley de enjuiciamiento civil, que es la principal ley procesal en el orden jurisdiccional civil y que, como manifiesta Cortés Domínguez ${ }^{30}$, conforma junto a otras leyes «el núcleo básico de nuestro ordenamiento procesal» $\mathrm{y}$, en segundo lugar, aquellas otras normas procesales que mencionen o se refieran a la traducción de documentos.

\section{Ley 1/2000, de 7 de enero, de Enjuiciamiento Civil}

La Ley 1/2000, de 7 de enero, de Enjuiciamiento Civil, en lo sucesivo LEC, se refiere a la traducción en el Título V, De las actuaciones judiciales, Capítulo III, De la inmediación, la publicidad y la lengua oficial, artículos 142.4 y 144.

El artículo 142, Lengua oficial, apartado 4, dispone:

Las actuaciones judiciales realizadas y los documentos presentados en el idioma oficial de una Comunidad Autónoma tendrán, sin necesidad de traducción al castellano, plena validez y eficacia, pero se procederá de oficio a su traducción cuando deban surtir efecto fuera de la jurisdicción de los órganos judiciales sitos en la Comunidad Autónoma, salvo si se trata de Comunidades Autónomas con lengua oficial propia coincidente. También se procederá a su traducción cuando así lo dispongan las leyes o a instancia de parte que alegue indefensión.

Por su parte, el artículo 144, Documentos redactados en idioma no oficial, establece:

1. A todo documento redactado en idioma que no sea el castellano o, en su caso, la lengua oficial propia de la Comunidad Autónoma de que se trate, se acompañará la traducción del mismo.

2. Dicha traducción podrá ser hecha privadamente y, en tal caso, si alguna de las partes la impugnare dentro de los cinco días siguientes desde el traslado, manifestando que no la tiene por fiel y exacta y expresando las razones de la discrepancia, el Secretario judicial

\footnotetext{
${ }^{30}$ Moreno Catena, V. y Cortés Domínguez, V., ob. cit., pág. 30.
} 
ordenará, respecto de la parte que exista discrepancia, la traducción oficial del documento, a costa de quien lo hubiese presentado.

No obstante, si la traducción oficial realizada a instancia de parte resultara ser sustancialmente idéntica a la privada, los gastos derivados de aquélla correrán a cargo de quien la solicitó.

Como podemos observar, el artículo 142.4 regula los supuestos en los que es necesaria la traducción de los documentos presentados en el idioma oficial de una Comunidad Autónoma pero nada expresa respecto a las personas habilitadas para hacer dichas traducciones.

En igual sentido, el artículo 144, al referirse a los documentos redactados en idioma no oficial, dispone que se ha de acompañar la traducción de los mismos, que podrá ser hecha privadamente, y que, si existe discrepancia, el Secretario judicial ordenará la traducción oficial del documento, pero no hacen mención alguna ni a las personas que han de hacer dicha traducción ni a quiénes deberán efectuar la traducción oficial del documento. Estos artículos expresan, pues, lo que debe hacerse pero dejan en la imprecisión cuáles son las personas habilitadas a tal efecto.

De las expresiones utilizadas por el legislador en el artículo 144, «dicha traducción podrá ser hecha privadamente» $\mathrm{y}$ «la traducción oficial del documento», parece deducirse que en el caso de «la traducción hecha privadamente» esta puede realizarse por cualquier persona que tenga un mero conocimiento de los idiomas de trabajo; sin embargo, cuando se hace referencia a la traducción oficial, entendemos, entonces, que dicha traducción solo podrá ser efectuada por aquellos traductores cuyas traducciones tengan carácter oficial.

Para saber qué traducciones tienen carácter oficial, hemos de remitirnos a la Disposición adicional décima sexta, Traducciones e interpretaciones de carácter oficial, de la Ley 2/2014, de 25 de marzo, de la Acción y del Servicio Exterior del Estado que dispone:

Reglamentariamente se determinarán los requisitos para que las traducciones e interpretaciones de una lengua extranjera al castellano y viceversa tengan carácter oficial. En todo caso, tendrán este carácter 
las certificadas por la Oficina de Interpretación de Lenguas del Ministerio de Asuntos Exteriores y de Cooperación, así como las realizadas por quien se encuentre en posesión del título de traductorintérprete jurado que otorga el Ministerio de Asuntos Exteriores y de Cooperación. Los requisitos para el otorgamiento de este título, así como el resto de elementos que conforman su régimen jurídico, se desarrollarán reglamentariamente. El traductor-intérprete jurado certificará con su firma y sello la fidelidad y exactitud de la traducción e interpretación.

También tendrán carácter oficial:

a) Las realizadas o asumidas como propias por una representación diplomática u oficina consular de España en el extranjero, siempre que se refieran a un documento público extranjero que se incorpora a un expediente o procedimiento iniciado o presentado ante dicha unidad administrativa y que deba resolver la Administración española.

b) Las realizadas por una representación diplomática u oficina consular de carrera extranjera en España, siempre que se refieran al texto de una ley de su país o a un documento público del mismo.

El carácter oficial de una traducción o interpretación implica que ésta pueda ser aportada ante órganos judiciales y administrativos en los términos que se determine reglamentariamente.

La traducción e interpretación que realice un traductor-intérprete jurado o una representación diplomática u oficina consular, podrá ser revisada por la Oficina de Interpretación de Lenguas del Ministerio de Asuntos Exteriores y de Cooperación a solicitud del titular del órgano administrativo, judicial, registro o autoridad competente ante quien se presente.

Por último, cabe reseñar que la LEC, en su Disposición final vigésima tercera, Medidas para facilitar la aplicación en España del Reglamento (CE) n. ${ }^{\circ}$ 1896/2006 del 
Parlamento Europeo y del Consejo, de 12 de diciembre de 2006, por el que se establece un proceso monitorio europeo; Disposición final vigésima cuarta, Medidas para facilitar la aplicación en España del Reglamento (CE) $n .^{\circ}$ 861/2007 del Parlamento Europeo y del Consejo, de 11 de julio de 2007, por el que se establece un proceso europeo de escasa cuantía; Disposición final vigésima quinta, Medidas para facilitar la aplicación en España del Reglamento (UE) $n .^{\circ}$ 1215/2012 del Parlamento y del Consejo, de 12 de diciembre de 2012, relativo a la competencia judicial, el reconocimiento y la ejecución de resoluciones judiciales en materia civil y mercantil y Disposición final vigésima sexta, Medidas para facilitar la aplicación en España del Reglamento (UE) n. ${ }^{\circ}$ 650/2012 del Parlamento Europeo y del Consejo, de 4 de julio de 2012, relativo a la competencia, la ley aplicable, el reconocimiento y la ejecución de las resoluciones, a la aceptación y la ejecución de los documentos públicos en materia de sucesiones «mortis causa» y a la creación de un certificado sucesorio europeo, hace alusión a la traducción de documentos en los siguientes términos:

Disposición final vigésima tercera, apartado 15:

Cuando deba ejecutarse en España un requerimiento europeo de pago, el demandante deberá presentar ante el Juzgado competente una traducción oficial al castellano o a la lengua oficial de la Comunidad Autónoma en cuyo territorio tengan lugar las actuaciones judiciales de dicho requerimiento, certificada en la forma prevista en el artículo 21 del Reglamento (CE) n. ${ }^{\circ}$ 1896/2006.

Disposición final vigésima cuarta, apartado 9:

Cuando deba ejecutarse en España una sentencia dictada en otro Estado miembro de la Unión Europea que ponga fin a un proceso europeo de escasa cuantía, el demandante deberá presentar ante el Juzgado competente una traducción oficial al castellano o a la lengua oficial de la Comunidad Autónoma en cuyo territorio tengan lugar las actuaciones judiciales del certificado de dicha sentencia, certificada en la forma prevista en el apartado 2 del artículo 21 del Reglamento (CE) n. ${ }^{\circ} 861 / 2007$. 
Disposición final vigésima quinta, apartado 1, Reglas sobre el reconocimiento de resoluciones de un Estado miembro de la Unión Europea al amparo del Reglamento (UE) $n .^{o} 1215 / 2012,3{ }^{a}$ :

La parte que desee invocar en España una resolución dictada en otro Estado miembro deberá presentar los documentos previstos en el artículo 37 del Reglamento (UE) n. ${ }^{\circ}$ 1215/2012, pudiendo el órgano judicial o la autoridad ante la cual se invoque la misma pedir las traducciones o transcripciones previstas en el apartado 2 de dicho artículo.

Disposición final vigésima quinta, apartado 2, Reglas sobre la ejecución de resoluciones con fuerza ejecutiva de un Estado miembro de la Unión Europea al amparo del Reglamento (UE) $n .^{o} 1215 / 2012,2{ }^{a}$ :

A efectos de la ejecución de una resolución con fuerza ejecutiva, el solicitante facilitará los documentos prevenidos en el artículo 42.1 del Reglamento (UE) n. ${ }^{\circ}$ 1215/2012 o los previstos en el artículo 42.2 del mismo Reglamento si se trata de una resolución que ordene una medida provisional o cautelar, así como, si lo exige el órgano judicial competente, la traducción del certificado prevenida en el artículo 42.3 de dicho Reglamento.

Sólo podrá exigirse al solicitante que presente una traducción de la resolución si no pueden continuarse las diligencias sin ella.

Disposición final vigésima quinta, apartado 3, No acreditación de la notificación del certificado y traducción de la resolución extranjera, $2^{a}$ y $3^{a}$ :

2. ${ }^{\text {a }}$ A los efectos de la aplicación del artículo 43.2 del Reglamento (UE) n. ${ }^{\circ}$ 1215/2012, la persona contra la que se inste la ejecución dispondrá de un plazo de cinco días para solicitar la traducción de la resolución extranjera, a contar desde la notificación del despacho de la ejecución, si no se le hubiese notificado anteriormente y no se hubiera 
adjuntado con la demanda de ejecución una traducción de dicha resolución.

3. ${ }^{a}$ Mientras no se le entregue dicha traducción quedará en suspenso el plazo previsto por el artículo 556.1 de esta ley para oponerse a la ejecución, así como el plazo de contestación previsto en el apartado siguiente. El juez sobreseerá la ejecución si en el plazo de un mes el ejecutante no aporta dicha traducción.

Disposición final vigésima sexta, apartado 4, Procedimiento de declaración de fuerza ejecutiva de una resolución, $2 .^{a}$ :

Si no se presentara la certificación prevista en el apartado anterior, el órgano judicial podrá fijar un plazo para su presentación, aceptar un documento equivalente o dispensar de ellos si considera que dispone de suficiente información.

Podrá pedir también el órgano judicial una traducción de los documentos realizada por una persona cualificada para realizar traducciones en uno de los Estados miembros.

Dichas Disposiciones finales, al igual que los anteriores artículos citados 142.4 y 144 , se refieren a la «traducción», a la «traducción oficial» y a la traducción realizada «por una persona cualificada» sin hacer referencia alguna a las personas que han de efectuar dicha traducción, a su cualificación o a quién ha de hacer la traducción oficial del documento.

Resumiendo, podemos afirmar que la LEC hace referencia a la traducción de documentos de manera genérica, a las traducciones privadas y a las traducciones oficiales, pero en ningún momento regula o hace mención a las personas que han de realizar dichas traducciones, es decir, al traductor.

Así pues, cuando la LEC menciona las traducciones oficiales, para saber qué traducciones tienen este carácter tendremos que recurrir, como anteriormente apuntamos, a la Disposición adicional décima sexta, Traducciones e interpretaciones de carácter oficial, de la Ley 2/2014, de 25 de marzo, de la Acción y el Servicio Exterior 
del Estado, que sí expresa de manera clara quiénes están habilitados legalmente para su realización: la Oficina de Interpretación de Lenguas del Ministerio de Asuntos Exteriores y de Cooperación, un Traductor-Intérprete Jurado y una representación diplomática u oficina consular.

Ley 60/2003, de 23 de diciembre, de arbitraje

La Ley 60/2003, de 23 de diciembre, de arbitraje no alude en su articulado la obligatoriedad de la traducción de documentos, sino que trata la innecesaridad de la misma en algunos casos. Así, el artículo 28, Idioma del arbitraje, apartado 2, dispone lo siguiente: «Los árbitros, salvo oposición de alguna de las partes, podrán ordenar que, sin necesidad de proceder a su traducción, cualquier documento sea aportado o cualquier actuación realizada en idioma distinto al del arbitraje».

Real Decreto 980/2013, de 13 de diciembre, por el que se desarrollan determinados aspectos de la Ley 5/2012, de 6 de julio, de mediación en asuntos civiles y mercantiles

Únicamente un artículo de este Real Decreto hace referencia a la traducción, en él se especifica directamente el carácter de la misma: una traducción jurada. Este es el artículo 14.3 que establece:

También podrán inscribirse mediadores reconocidos en cualquier otro Estado miembro de la Unión Europea, que acompañarán por medios electrónicos a su solicitud una certificación oficial del registro de su país o certificación de su condición de mediador expedida por la autoridad competente del Estado de que se trate y una traducción jurada de la misma.

Ley 29/2015, de 30 de julio, de cooperación jurídica internacional en materia civil

Tres son los artículos de esta ley que hacen mención a la traducción y lo hacen en los siguientes términos:

Título Preliminar, Disposiciones generales, Capítulo I., Disposiciones generales, artículo 11, Idioma: 
1. Las solicitudes de cooperación jurídica internacional, y sus documentos adjuntos, que se dirijan a una autoridad extranjera, deberán acompañarse de una traducción a una lengua oficial del Estado requerido o aceptada por éste.

2. Las solicitudes de cooperación jurídica internacional dirigidas a las autoridades españolas, y sus documentos adjuntos, deberán acompañarse de una traducción con arreglo al artículo 144 de la Ley de Enjuiciamiento Civil.

Título Preliminar, Disposiciones generales, Capítulo II, De los actos de notificación y traslado de documentos judiciales, artículo 25, Idioma:

1. Sin perjuicio de lo que pueda exigir la ley del Estado de destino, los documentos objeto de notificación o traslado al extranjero deberán acompañarse de una traducción a la lengua oficial del Estado de destino o a una lengua que el destinatario entienda.

2. Si la comunicación proviene de autoridades extranjeras y se dirige a un destinatario en España, los documentos deberán ir acompañados de una traducción al español o, en su caso, a la lengua oficial propia de la Comunidad Autónoma de que se trate, o a una lengua que el destinatario entienda en los términos establecidos en el apartado anterior.

Título V, Del reconocimiento y ejecución de resoluciones judiciales y documentos públicos extranjeros, del procedimiento de exequátur y de la inscripción en Registros públicos, Capítulo IV, Del procedimiento judicial de exequátur, artículo 54, Proceso:

4. La demanda se ajustará a los requisitos del artículo 399 de la Ley de Enjuiciamiento Civil y deberá ir acompañada, de: [...]

d) Las traducciones pertinentes con arreglo al artículo 144 de la Ley de Enjuiciamiento Civil.

Esta ley habla de traducciones pero nada dice en cuanto al tipo de traducción ni a las personas que han de efectuar las mismas. 


\subsection{Orden jurisdiccional penal}

Al igual que en el orden jurisdiccional civil y con la misma pretensión, en este orden jurisdiccional van a ser objeto de nuestro estudio las normas procesales especializadas, propias y de aplicación directa en el orden jurisdiccional penal. Consideraremos, por una parte, la ley procesal básica en este orden, que es la Ley de Enjuiciamiento Criminal aprobada por el Real decreto de 14 de septiembre de 1882, y, por otra parte, aquellas otras normas procesales que regulen o mencionen la traducción de documentos y la figura del traductor.

Real decreto de 14 de septiembre de 1882 por el que se aprueba la Ley de Enjuiciamiento Criminal

La importancia de la traducción en los procedimientos judiciales penales ha sido puesta de manifiesto por la Ley Orgánica 5/2015, de 27 de abril, por la que se modifican la Ley de Enjuiciamiento Criminal y la Ley Orgánica 6/1985, de 1 de julio, del Poder Judicial, para transponer la Directiva 2010/64/UE, de 20 de octubre de 2010, relativa al derecho a interpretación y a traducción en los procesos penales y la Directiva 2012/13/UE, de 22 de mayo de 2012, relativa al derecho a la información en los procesos penales.

Uno de los rasgos más relevantes de esta reforma es que los traductores judiciales deberán ser designados entre aquellos incluidos en los listados elaborados por la Administración, concediendo al Gobierno un plazo máximo para la presentación de un Proyecto de ley de creación de un Registro Oficial de Traductores e Intérpretes judiciales con la debida habilitación y cualificación.

Esto significa que la Consejería de Justicia debe prestar ya una especial atención a la cualificación de los traductores que actúan en los procedimientos judiciales. Es imprescindible garantizar una traducción de calidad para colmar las exigencias de este derecho a la traducción, lo que solo puede obtenerse mediante una cuidadosa selección y organización de su cometido.

La Ley de Enjuiciamiento Criminal, aprobada por el Real Decreto de 14 de septiembre de 1882, en adelante LECrim, dedica su Título V al derecho a la defensa, a la asistencia 
jurídica gratuita y a la traducción e interpretación en los juicios criminales, regulando en su Capítulo II el derecho a la traducción e interpretación.

Respecto a la traducción, dice el artículo 123, apartado 1,d, de la LECrim:

1. Los imputados o acusados que no hablen o entiendan el castellano o la lengua oficial en la que se desarrolle la actuación tendrán los siguientes derechos: [...]

d) Derecho a la traducción escrita de los documentos que resulten esenciales para garantizar el ejercicio del derecho a la defensa. Deberán ser traducidos, en todo caso, las resoluciones que acuerden la prisión del imputado, el escrito de acusación y la sentencia.

Estableciendo el párrafo segundo del apartado «e» de dicho artículo que «Los gastos de traducción e interpretación derivados del ejercicio de estos derechos serán sufragados por la Administración, con independencia del resultado del proceso».

Por otra parte, el artículo 123, en los apartados 3 y 4, dispone:

3. En el caso de la letra d) del apartado 1, podrá prescindirse de la traducción de los pasajes de los documentos esenciales que, a criterio del Juez, Tribunal o funcionario competente, no resulten necesarios para que el imputado o acusado conozca los hechos que se le imputan.

Excepcionalmente, la traducción escrita de documentos podrá ser sustituida por un resumen oral de su contenido en una lengua que comprenda, cuando de este modo también se garantice suficientemente la defensa del imputado o acusado.

4. La traducción se deberá llevar a cabo en un plazo razonable y desde que se acuerde por parte del Tribunal o Juez o del Ministerio Fiscal quedarán en suspenso los plazos procesales que sean de aplicación.

A tenor del artículo 124 de dicha ley: 
1. El traductor o intérprete judicial será designado de entre aquellos que se hallen incluidos en los listados elaborados por la Administración competente. Excepcionalmente, en aquellos supuestos que requieran la presencia urgente de un traductor o de un intérprete, y no sea posible la intervención de un traductor o intérprete judicial inscrito en las listas elaboradas por la Administración, en su caso, conforme a lo dispuesto en el apartado 5 del artículo anterior, se podrá habilitar como intérprete o traductor judicial eventual a otra persona conocedora del idioma empleado que se estime capacitado para el desempeño de dicha tarea.

2. El intérprete o traductor designado deberá respetar el carácter confidencial del servicio prestado.

3. Cuando el Tribunal, el Juez o el Ministerio Fiscal, de oficio o a instancia de parte, aprecie que la traducción o interpretación no ofrecen garantías suficientes de exactitud, podrá ordenar la realización de las comprobaciones necesarias y, en su caso, ordenar la designación de un nuevo traductor o intérprete. En este sentido, las personas sordas o con discapacidad auditiva que aprecien que la interpretación no ofrece garantías suficientes de exactitud, podrán solicitar la designación de un nuevo intérprete.

Por último, el artículo 125 de la LECrim preceptúa lo siguiente:

1. Cuando se pongan de manifiesto circunstancias de las que pueda derivarse la necesidad de la asistencia de un intérprete o traductor, el Presidente del Tribunal o el Juez, de oficio o a instancia del Abogado del imputado o acusado, comprobará si éste conoce y comprende suficientemente la lengua oficial en la que se desarrolle la actuación y, en su caso, ordenará que se nombre un intérprete o un traductor conforme a lo dispuesto en el artículo anterior y determinará qué documentos deben ser traducidos. 
2. La decisión del Juez o Tribunal por la que se deniegue el derecho a la interpretación o a la traducción de algún documento o pasaje del mismo que la defensa considere esencial, o por la que se rechacen las quejas de la defensa con relación a la falta de calidad de la interpretación o de la traducción, será documentada por escrito.

Si la decisión hubiera sido adoptada durante el juicio oral, la defensa del imputado o acusado podrá hacer constar en el acta su protesta.

Contra estas decisiones judiciales podrá interponerse recurso de conformidad con lo dispuesto en esta Ley.

Como hemos puesto de manifiesto, el traductor judicial será designado de entre aquellos que se hallen incluidos en los listados elaborados por la Administración competente. A este respecto, la Disposición final primera, Registro Oficial de traductores e intérpretes judiciales, de la Ley Orgánica 5/2015, de 27 de abril, por la que se modifican la Ley de Enjuiciamiento Criminal y la Ley Orgánica 6/1985, de 1 de julio, del Poder Judicial, dispone:

El Gobierno presentará, en el plazo máximo de un año desde la publicación de esta Ley, un Proyecto de ley de creación de un Registro Oficial de Traductores e Intérpretes judiciales para la inscripción de todos aquellos profesionales que cuenten con la debida habilitación y cualificación, con el fin de elaborar las listas de traductores e intérpretes a que se refiere el artículo 124 de la Ley de Enjuiciamiento Criminal. La inscripción en este Registro Oficial será requisito necesario para la actuación de estos profesionales por designación del Juez o del Secretario judicial ante la Administración de Justicia y en las diligencias policiales en las que sea necesaria su presencia, sin perjuicio de las excepciones que se establezcan.

A efectos de proceder a la inscripción en este Registro Oficial, el Ministerio de Justicia podrá solicitar el cumplimiento de otros requisitos diferentes a la formación o titulación que se establezca reglamentariamente en función del idioma de que se trate. Estos 
requisitos deberán ser proporcionados y no discriminatorios y podrán basarse en la experiencia del profesional, en el conocimiento adicional de cuestiones procedimentales o jurídicas, y en el cumplimiento de deberes deontológicos previstos en la ley.

La norma reguladora de este Registro Oficial determinará sus condiciones y términos de funcionamiento.

Pese a lo dispuesto en la Ley Orgánica 5/2015, de 27 de abril, por la que se modifican la Ley de Enjuiciamiento Criminal y la Ley Orgánica 6/1985, de 1 de julio, del Poder Judicial, hasta el día de la fecha dicho registro no ha sido creado, por lo que no se puede dar cumplimiento a lo establecido en el artículo 124 transcrito, al no existir lista alguna de los profesionales que cuenten con la debida habilitación y cualificación para actuar ante la Administración de Justicia. Actualmente las traducciones judiciales son realizadas bien por las personas que pertenecen a la Administración de Justicia o por empresas privadas contratadas por la misma a tales fines en el caso de que esté licitado el servicio.

Centrándonos en las personas que pertenecen a la Administración de Justicia, vemos que el III Convenio colectivo único para el personal laboral de la Administración General del Estado, registrado y publicado por Resolución de 3 de noviembre de 2009, de la Dirección General de Trabajo, que a tenor de su artículo 1 será de aplicación general al personal laboral que presta servicios en la Administración de Justicia, incluye la traducción directa e inversa de distintos idiomas en el área funcional de gestión y servicios comunes. Dicho Convenio considera a los traductores en general, y por ende a los judiciales, como técnicos superiores de gestión y servicios comunes, pertenecientes al grupo profesional 3, cuya formación exigida es el Título de Bachillerato, Bachillerato Unificado Polivalente o Formación Profesional de Técnico Superior o Técnico Especialista, o equivalente. Por lo tanto, los traductores judiciales pertenecientes a la Administración de Justicia presentan las siguientes características:

Son personal laboral.

$>$ Se incluyen en el área funcional de gestión y servicios comunes.

$>$ Tienen la categoría profesional de técnico superior. 
$>$ Pertenecen al grupo profesional 3.

> Su formación es: Título de Bachillerato, Bachillerato Unificado Polivalente o Formación Profesional de Técnico Superior o Técnico Especialista, o equivalente.

Por lo que se refiere a las personas designadas por las empresas privadas contratadas por la Administración de Justicia para hacer las traducciones judiciales, en aquellos supuestos en los que está licitado el servicio, poco se puede decir sobre su categoría profesional, ya que esta depende de la contratación de cada empresa.

En definitiva, en el orden jurisdiccional penal, pese a las grandes expectativas creadas a raíz de las modificaciones a las que hemos hecho referencia, la situación de la figura del traductor con cualificación adecuada queda desdibujada en tanto en cuanto las traducciones judiciales se vienen haciendo por el personal de la Administración de Justicia que, pese a su existencia, no posee la licenciatura o el grado en Traducción e Interpretación, siendo su formación, como hemos apuntado, el Título de Bachillerato, Bachillerato Unificado Polivalente o Formación Profesional de Técnico Superior o Técnico Especialista, o equivalente, y por el personal de la empresa que tiene contratado el servicio; empresa a la que nadie le exige la capacitación específica que han de tener las personas a las que contrata para la realización de las traducciones judiciales.

\section{Ley 4/1985, de 21 de marzo, de Extradición Pasiva}

Esta ley, reguladora de las condiciones, los procedimientos y los efectos de la extradición pasiva, se refiere a la traducción cuando en su artículo 7.2, en relación con los documentos que han de acompañar a la solicitud de extradición, dispone lo siguiente: «Los referidos documentos, originales o en copia auténtica, se acompañarán de una traducción oficial al español».

Por tanto, si bien no explicita de forma directa quiénes han de ser las personas que han de realizar la traducción al español, de una manera indirecta, al determinar el carácter oficial de la traducción, está estableciendo que la traducción se deberá llevar a cabo por aquellos profesionales cuyas traducciones, según dispone la ley, tienen carácter oficial, que son las que hemos referido al analizar la figura del traductor en el orden jurisdiccional civil. 
Ley 23/2014, de 20 de noviembre, de reconocimiento mutuo de resoluciones penales en la Unión Europea

En cuanto a la traducción y a la figura del traductor, la Ley 23/2014, de 20 de noviembre, de reconocimiento mutuo de resoluciones penales en la Unión Europea, en su Título I, Capítulo I, Transmisión por las autoridades judiciales españolas de instrumentos de reconocimiento mutuo, dispone, en su artículo 7.3, lo siguiente en cuanto a la emisión y documentación de órdenes y resoluciones para su ejecución al amparo del principio de reconocimiento mutuo:

El certificado o el formulario se traducirán a la lengua oficial o a una de las lenguas oficiales del Estado miembro al que se dirija o, en su caso, a una lengua oficial de las instituciones comunitarias que hubiera aceptado dicho Estado, salvo que disposiciones convencionales permitan, en relación con ese Estado, su remisión en español.

La resolución penal sólo será objeto de traducción cuando así se requiera por la autoridad judicial de ejecución.

Por otra parte, en el Capítulo II del mismo Título, Reconocimiento y ejecución por las autoridades judiciales españolas de instrumentos de reconocimiento mutuo, el artículo 17, Traducción del certificado, establece:

1. Cuando el formulario o el certificado no venga traducido al español, se devolverá inmediatamente a la autoridad judicial del Estado emisor que lo hubiera firmado para que lleve a cabo la traducción correspondiente, salvo que un convenio en vigor con dicho Estado o una declaración depositada ante la Secretaría General del Consejo de la Unión Europea permitan el envío en esa otra lengua.

2. No será obligatorio que la resolución judicial en que se basa el certificado se reciba traducida al español, sin perjuicio de que la autoridad judicial solicite su traducción cuando lo considere imprescindible para su ejecución. 
Mientras que en el artículo 27.1 y 3, Tránsito de personas por territorio español en ejecución de una orden europea o resolución judicial transmitida por otro Estado miembro, se hace referencia a la traducción de la siguiente manera:

1. El Ministerio de Justicia será competente para autorizar el tránsito por territorio español de una persona que esté siendo trasladada desde el Estado de ejecución de una orden europea de detención y entrega o de una resolución por la que se impone una pena o medida privativa de libertad al Estado de emisión, siempre que aquél le remita la solicitud de tránsito acompañada de una copia del certificado emitido para la ejecución de la resolución.

El Ministerio de Justicia podrá solicitar al Estado de emisión que le remita una copia del formulario o del certificado traducida al español.

3. El Ministerio de Justicia comunicará su decisión a la autoridad competente del Estado de emisión en el plazo máximo de una semana desde la recepción de la solicitud, salvo en el caso en que hubiera pedido la traducción del formulario o certificado, en cuyo caso podrá aplazar la decisión hasta que reciba la traducción.

Por último, la ley, en su Título VIII, Resoluciones de decomiso, Capítulo I, Disposiciones generales, artículo 171.1, c, Suspensión de la ejecución de una resolución de decomiso, preceptúa:

1. El Juez de lo Penal competente podrá suspender la ejecución de una resolución de decomiso transmitida en los siguientes supuestos:

c) Cuando considere necesario traducir, sin repercutir su coste al Estado de emisión, la resolución de decomiso o partes de ella, por el tiempo necesario para obtener su traducción.

Como vemos, la ley habla simplemente de traducción de documentos sin hacer más consideraciones. En ningún momento determina cómo ha de ser o quién ha de realizar la traducción. 


\subsection{Orden jurisdiccional contencioso-administrativo}

Cuando entramos en el análisis del orden contencioso-administrativo observamos que ni en la Ley 29/1998, de 13 de julio, reguladora de la Jurisdicción ContenciosaAdministrativa, que es la ley procesal básica en dicho orden jurisdiccional, ni en la Ley 52/1997, de 27 de noviembre, de Asistencia Jurídica al Estado e Instituciones Públicas, se hace mención alguna ni a la traducción ni a la figura del traductor. No hay ninguna referencia en las normas especializadas, propias y de aplicación directa en este orden jurisdiccional a la traducción de documentos.

\subsection{Orden jurisdiccional social}

Al igual que en el orden jurisdiccional contencioso-administrativo, en el orden jurisdiccional social las normas especializadas, propias y de aplicación directa en este orden jurisdiccional no aluden en su texto a la traducción.

En este orden jurisdiccional, ni la Ley 36/2011, de 10 de octubre, reguladora de la jurisdicción social, que es la ley procesal básica en dicho orden, ni las demás normas procesales mencionan la traducción de documentos.

\subsection{Disposiciones comunes a todos los órdenes jurisdiccionales}

En este subapartado, el objeto de nuestro estudio son aquellas normas procesales que son comunes a los cuatro órdenes jurisdiccionales que hemos analizado. Sin embargo, a pesar de que la LEC es también común a todos los órdenes por su carácter de derecho supletorio, pues a tenor de su artículo 4 «en defecto de disposiciones en las leyes que regulan los procesos penales, contencioso-administrativos, laborales y militares, serán de aplicación, a todos ellos, los preceptos de la presente Ley», no vamos a referirnos a ella en tanto en cuanto ya ha sido objeto de análisis en el subapartado 4.1.

\section{Ley Orgánica 6/1985, de 1 de julio, del Poder Judicial}

La LOPJ, que es la ley procesal básica de aplicación directa en todos los órdenes jurisdiccionales, únicamente se refiere a la traducción, cuando habla de la oralidad, 
publicidad y lengua oficial de las actuaciones judiciales, en su artículo 231.4. Dicho precepto dispone:

4. Las actuaciones judiciales realizadas y los documentos presentados en el idioma oficial de una Comunidad Autónoma tendrán, sin necesidad de traducción al castellano, plena validez y eficacia. De oficio se procederá a su traducción cuando deban surtir efecto fuera de la jurisdicción de los órganos judiciales sitos en la Comunidad Autónoma, salvo si se trata de Comunidades Autónomas con lengua oficial propia coincidente. También se procederá a su traducción cuando así lo dispongan las leyes o a instancia de parte que alegue indefensión.

Esta ley habla de traducción de documentos sin aportar nada a la conceptualización de la persona que ha de hacer la traducción.

\section{Ley 1/1996, de 10 de enero, de Asistencia Jurídica Gratuita}

En último lugar, la Ley 1/1996, de 10 de enero, que tiene por objeto determinar el contenido y alcance del derecho a la asistencia jurídica gratuita y regular el procedimiento para su reconocimiento y efectividad, se refiere a la traducción de documentos en los siguientes términos:

Artículo 50:

1. El derecho de asistencia jurídica gratuita reconocido al amparo de esta Sección comprende todas las prestaciones indicadas en el artículo 6, con excepción de su apartado 2, con la extensión temporal del artículo 7, y, además: [...]

b) La traducción de los documentos presentados por el beneficiario a instancias del Juzgado o Tribunal o de la autoridad competente y que sean necesarios para resolver el asunto.

Artículo 51, Solicitud del derecho, párrafo segundo del apartado 3: 
Cuando una solicitud o la documentación correspondiente se reciban en una lengua no aceptada en España, serán inmediatamente devueltas a quien los hubiera presentado para que proceda a su traducción y presentación en el plazo de 15 días contados desde la recepción del requerimiento.

Artículo 52:

Las personas físicas que tengan su residencia habitual o su domicilio en España que pretendan beneficiarse de asistencia jurídica gratuita en otro Estado miembro de la Unión Europea para un litigio transfronterizo de los previstos en este Capítulo podrán acceder en España a los siguientes derechos: [...]

b) Traducción de la solicitud y de la documentación acreditativa necesaria que deba presentarse a las autoridades de dicho Estado miembro.

Artículo 54:

Cuando la autoridad competente de otro Estado miembro deniegue la solicitud de justicia gratuita realizada desde España con ejercicio de los derechos del artículo 52, se exigirá, si concurren las circunstancias previstas en el artículo 19, el reintegro de los gastos correspondientes a las traducciones.

Obsérvese que al igual que la mayoría de las demás leyes analizadas, la ley de asistencia jurídica gratuita únicamente menciona la traducción de documentos, sin hacer alusión expresa a la clase de traducción ni a las personas cualificadas para realizar la misma.

\section{Conclusiones}

Finalizado el análisis normativo efectuado, son varias las reflexiones extraídas de nuestro estudio acerca de la realidad jurídica de la traducción y la situación actual de la figura del traductor en las normas procesales, comunes y especializadas, que regulan los distintos órdenes jurisdiccionales: 
Primero, es evidente que existe una escasa e imprecisa regulación de la traducción y casi nula regulación de las personas que han de llevar a cabo las traducciones y de su capacitación, limitándose en la gran mayoría de los casos a una simple alusión a la obligatoriedad de la traducción.

Segundo, consideramos que, aún a día de hoy, prevalece la errónea equiparación de la figura del profesional de la traducción con una mera persona conocedora de un idioma. Es más, tal y como hemos podido comprobar en nuestro análisis, en múltiples ocasiones basta con que se acredite el conocimiento del idioma extranjero para que se considere capacitada a la persona para hacer traducciones en un campo tan especializado como puede llegar a ser la traducción en el ámbito procesal. Se obvia totalmente la capacitación académica a pesar de la existencia de un Grado Superior en Traducción e Interpretación, lo cual nos resulta atroz, dado que no se puede llegar a comprender que se capacite a una persona que no tiene titulación universitaria alguna, solo los conocimientos notorios de un idioma, para efectuar traducciones en los distintos órdenes jurisdiccionales. Es más, vemos que el III Convenio colectivo único para el personal laboral de la Administración General del Estado, registrado y publicado por Resolución de 3 de noviembre de 2009, de la Dirección General de Trabajo, considera a los traductores en general como técnicos superiores de gestión y servicios comunes pertenecientes al grupo profesional 3, cuya formación requerida es el Título de Bachillerato, Bachillerato Unificado Polivalente o Formación Profesional de Técnico Superior o Técnico Especialista, o equivalente; lo que corrobora la falta de capacitación académica a la que hacemos mención.

Tercero, evidenciado lo anterior, constatamos, por tanto, que, por lo general, en las normas procesales españolas, salvo en aquellos supuestos en los que se exige o recomienda la traducción oficial del documento, no se tiene en consideración alguna la fidelidad de la traducción, pues traducir conlleva, como hemos puesto de manifiesto, algo más que un mero trasvase de lenguas, supone reconocer y trasladar, también, los elementos culturales inherentes al documento junto con 
los conocimientos temáticos precisos sobre la materia y el campo de actuación sobre el que versa el mismo. Jamás podrá existir fidelidad en la traducción si se conocen las lenguas de partida y de llegada pero no las distintas culturas involucradas, ni el campo especializado en donde se incardina la traducción.

Y cuarto, terminamos estas conclusiones subrayando que, de momento, esta situación no tiene visos de ser regulada de forma adecuada, es decir, dándole a la profesión de la traducción el reconocimiento que merece y considerando a la figura del traductor como un profesional titulado en la materia, pues todas las esperanzas que abrió al respecto la Ley Orgánica 5/2015, de 27 de abril, se han visto frustradas, en tanto en cuanto, a día de hoy, el Registro Oficial de Traductores e Intérpretes judiciales para la inscripción de todos aquellos profesionales que cuenten con la debida habilitación y cualificación, al que hace referencia la Disposición final primera de dicha ley orgánica, sigue sin haberse creado. 